\title{
A NOVEL MIXED-MODE CCII-BASED FILTER
}

\author{
MUHAMMAD TAHER ABUELMA'ATTI* and ABDULWAHAB BENTRCIA
}

King Fahd University of Petroleum and Minerals, Box 203, Dhahran 31261, Saudi Arabia

(Received 9 September 2003; In final form 14 November 2003)

\begin{abstract}
A new mixed-mode biquad circuit is presented. The circuit uses five second-generation current conveyors, seven resistors, and two grounded capacitors and can realize lowpass, highpass, bandpass, notch, lowpass notch, highpass notch and allpass responses from the same topology. The circuit can be driven by voltage or current and its output can be voltage or current. The parameters $\omega_{0}$ and $\omega_{0} / Q_{0}$ enjoy independent electronic tunability. Simulation results are included.
\end{abstract}

Keywords: Active filters; Current conveyors

\section{INTRODUCTION}

At present, there is a growing interest in designing various active filter transfer functions using current conveyors. This is attributed to their low power consumption, low-supply voltages, higher signal bandwidths, greater linearity, and larger dynamic range $[1,2]$. Thus, a number of circuit realizations for universal current-mode and voltage-mode filters were proposed; see, for example, Refs. [3-23] and the references cited therein. While some of these realizations use single-output plus- and/or minus-type secondgeneration current conveyors (CCIIs) to realize current- and voltage-mode transfer functions [3-9, 16-21,23], other realizations use dual- and/or multiple-output CCIIs [10-15,22].

In analog signal processing applications, it may be desirable to have active filters with input currents and/or voltages and output currents and/or voltages, that is, mixedmode filters [24-26]. Careful inspection of the available literature shows that while mixedmode realizations with input current and output voltage are available [24-26], no circuit realization is available for realizing a generalized mixed-mode active filter with input current or voltage and output current or voltage. It is the major intention of this article to present such a generalized mixed-mode circuit using single- and dual-output plus- and minus-type CCIIs.

\footnotetext{
* Corresponding author. E-mail: mtaher@kfupm.edu.sa
} 


\section{PROPOSED CIRCUIT}

The proposed circuit is shown in Figure 1. Routine analysis yields the transfer functions given by

$$
V_{\text {out }}=\frac{R_{4} R_{7}}{R_{2} R_{3}} \frac{N(s)}{D(s)}
$$

and

$$
I_{\text {out }}=-\frac{R_{4}}{R_{2} R_{3}} \frac{N(s)}{D(s)}
$$

where

$$
\begin{aligned}
N(s)= & s^{2} V_{\mathrm{in} 3}-\frac{s V_{\mathrm{in} 4}}{C_{1} R_{6}}-\frac{s V_{\mathrm{in} 2}}{C_{1} R_{5}}+\frac{V_{\mathrm{in} 1}}{C_{1} C_{2} R_{1} R_{5}} \\
& +s^{2} R_{3} I_{\mathrm{in} 3}-\frac{s I_{\mathrm{in} 2}}{C_{1}}+\frac{I_{\mathrm{in} 1}}{C_{1} C_{2} R_{5}}
\end{aligned}
$$

and

$$
D(s)=s^{2}+\frac{s R_{4}}{C_{1} R_{3} R_{6}}+\frac{R_{4}}{C_{1} C_{2} R_{1} R_{3} R_{5}}
$$

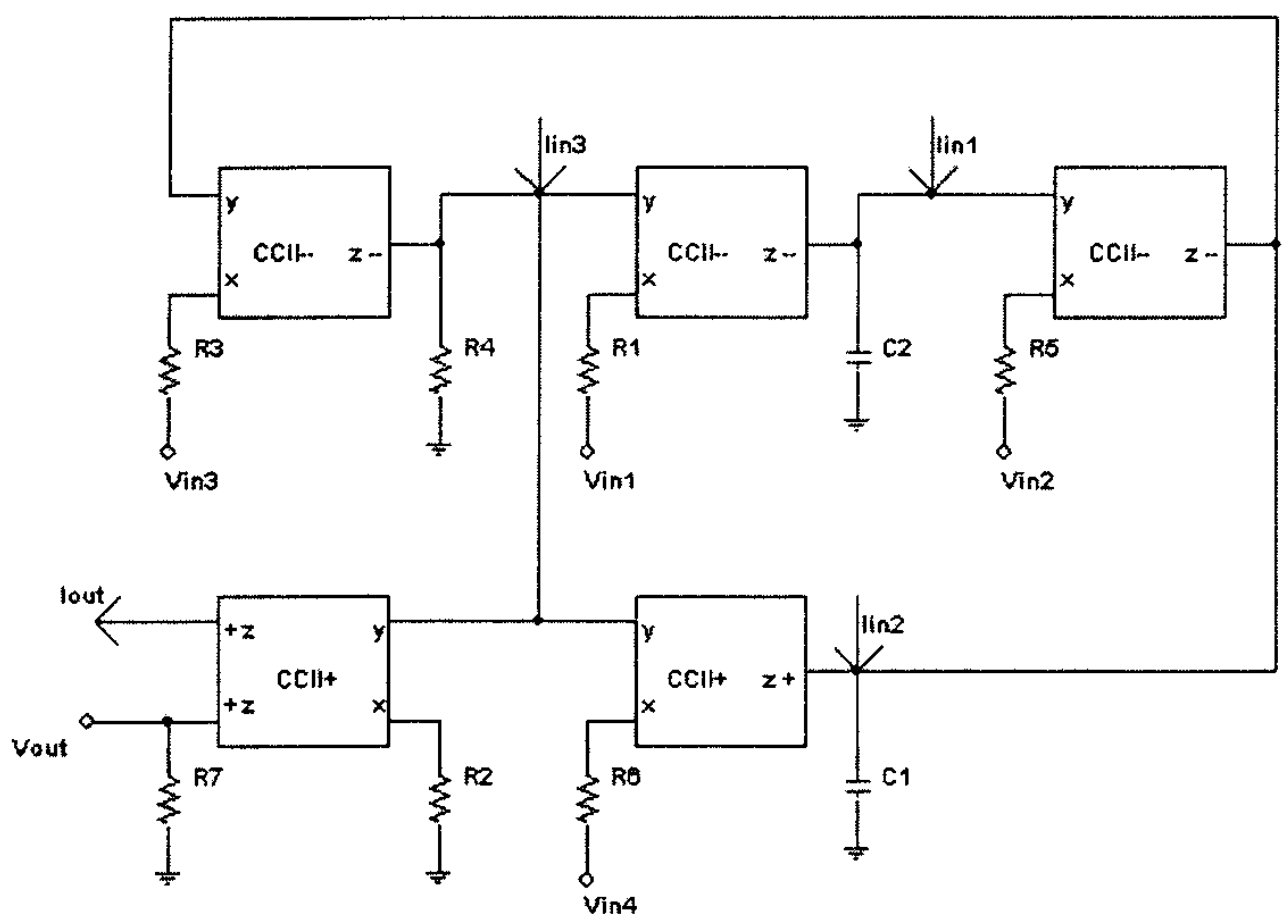

FIGURE 1 Proposed mixed-mode CCII-based filter. 
Inspection of Eqs. (3) and (4) shows that various inverted and non-inverted mixed-mode filter functions, with input voltage or current and output voltage or current, can be realized. For example:

1. With $I_{\text {in } 1}=I_{\text {in } 2}=I_{\text {in } 3}=0$, the following voltage-mode responses, with input voltages and output voltage, and mixed-mode responses, with input voltages and output current are obtained:

a. A non-inverted highpass filter (HPF) with $V_{\mathrm{in} 1}=V_{\mathrm{in} 2}=V_{\mathrm{in} 4}=0$.

b. A non-inverted lowpass filter (LPF) with $V_{\mathrm{in} 2}=V_{\mathrm{in} 3}=V_{\mathrm{in} 4}=0$.

c. An inverted bandpass filter (BPF) with $V_{\text {in } 1}=V_{\text {in } 3}=V_{\text {in2 }}=0$ or $V_{\text {in } 1}=V_{\text {in } 3}=V_{\text {in } 4}=0$.

d. A non-inverted notch filter (NF) with $V_{\text {in } 1}=V_{\text {in3 }}$ and $V_{\text {in } 2}=V_{\text {in } 4}=0$.

e. In case $\mathrm{d}$, a notch, lowpass notch, and highpass notch can be obtained by adjusting $R_{3}$ and $R_{4}$.

f. A non-inverted allpass filter (APF) with $R_{3}=R_{4}$ and $V_{\text {in2 }}=0, V_{\text {in } 1}=V_{\text {in3 }}=V_{\text {in4 }}$ or with $R_{3}=R_{4}, R_{5}=R_{6}$, and $V_{\text {in } 4}=0, V_{\text {in } 1}=V_{\text {in } 2}=V_{\text {in } 3}$.

In cases $1 \mathrm{a}-\mathrm{f}$, the polarities are referred to the voltage-mode outputs. For the mixed-mode outputs, the polarities are the opposite; for example, in case la an inverted HPF will be obtained.

2. With $V_{\text {in } 1}=V_{\text {in } 2}=V_{\text {in } 3}=0$, the following current-mode responses, with input currents and output current, and mixed-mode responses, with input currents and output voltage, are obtained:

a. A non-inverting LPF with $I_{\text {in } 2}=I_{\text {in } 3}=0$.

b. An inverting BPF with $I_{\text {in } 1}=I_{\text {in } 3}=0$.

c. A non-inverting HPF with $I_{\text {in } 1}=I_{\text {in } 2}=0$.

d. A non-inverting NF with $I_{\text {in } 1}=I_{\text {in } 3}$ and $I_{\text {in } 2}=0$.

e. In case $\mathrm{d}$, a notch, lowpass notch, and high pass notch can be obtained by adjusting $R_{1}$ and $R_{5}$.

f. A non-inverting APF with $I_{\text {in } 1}=I_{\text {in } 2}=I_{\text {in } 3}$ and $R_{1}=R_{4}=R_{6}$.

Again in cases $2 \mathrm{a}-\mathrm{f}$, the polarities are referred to the mixed-mode outputs. For the currentmode outputs, the polarities are the opposite; for example, in case $2 \mathrm{a}$ an inverted LPF will be obtained.

Inspection of Eq. (4) shows that in all cases the parameters $\omega_{\mathrm{o}}^{2}$ and $\omega_{\mathrm{o}} / Q_{\mathrm{o}}$ are given by

$$
\omega_{\mathrm{o}}^{2}=\frac{R_{4}}{R_{1} R_{3} R_{5} C_{1} C_{2}}
$$

and

$$
\frac{\omega_{\mathrm{o}}}{Q_{\mathrm{o}}}=\frac{R_{4}}{R_{3} R_{6} C_{1}}
$$

Thus the parameter $\omega_{\mathrm{o}}^{2}$ can be controlled by adjusting the resistances $R_{1}$ and/or $R_{5}$ without disturbing the parameter $\omega_{\mathrm{o}} / Q_{\mathrm{o}}$, and the parameter $\omega_{\mathrm{o}} / Q_{\mathrm{o}}$ can be controlled by adjusting resistance $R_{6}$ without disturbing the parameter $\omega_{\mathrm{o}}^{2}$. Thus, the proposed circuit enjoys the attractive feature of independent electronic tunability of the parameters $\omega_{\mathrm{o}}^{2}$ and $\omega_{\mathrm{o}} / Q_{\mathrm{o}}$.

Using Eqs. (5) and (6), it is easy to show that all the passive sensitivities of the parameters $\omega_{\mathrm{o}}$ and $\omega_{\mathrm{o}} / Q_{\mathrm{o}}$ are less than unity. Thus the circuit parameters enjoy low passive sensitivities. 


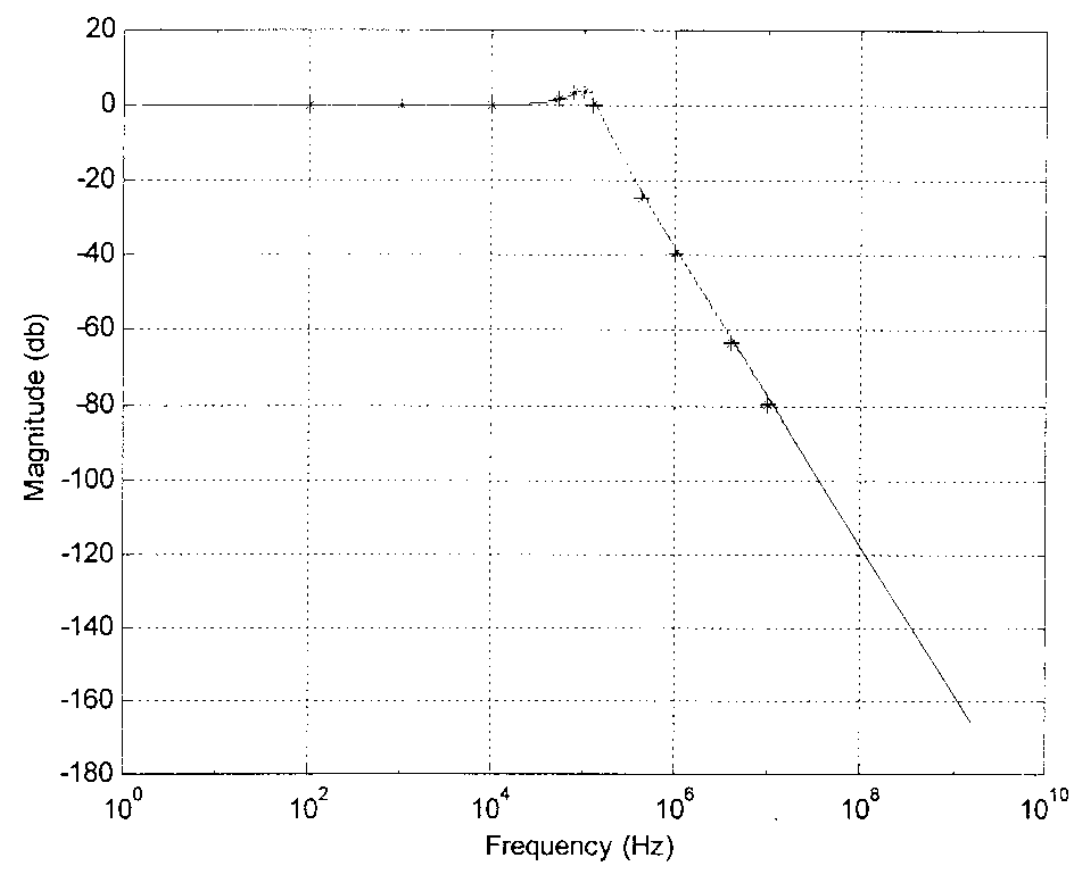

FIGURE 2 Calculated (-) and simulated (**) current-mode lowpass response.

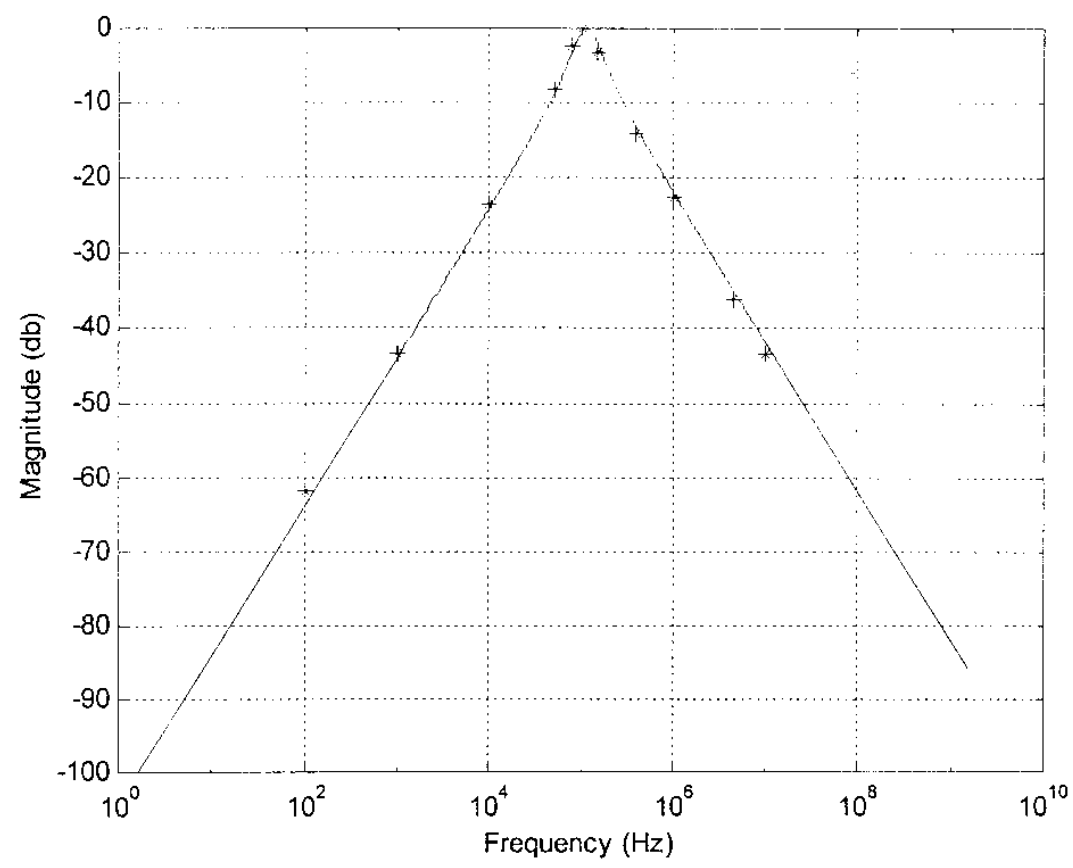

FIGURE 3 Calculated (-) and simulated (**) current-mode bandpass response. 


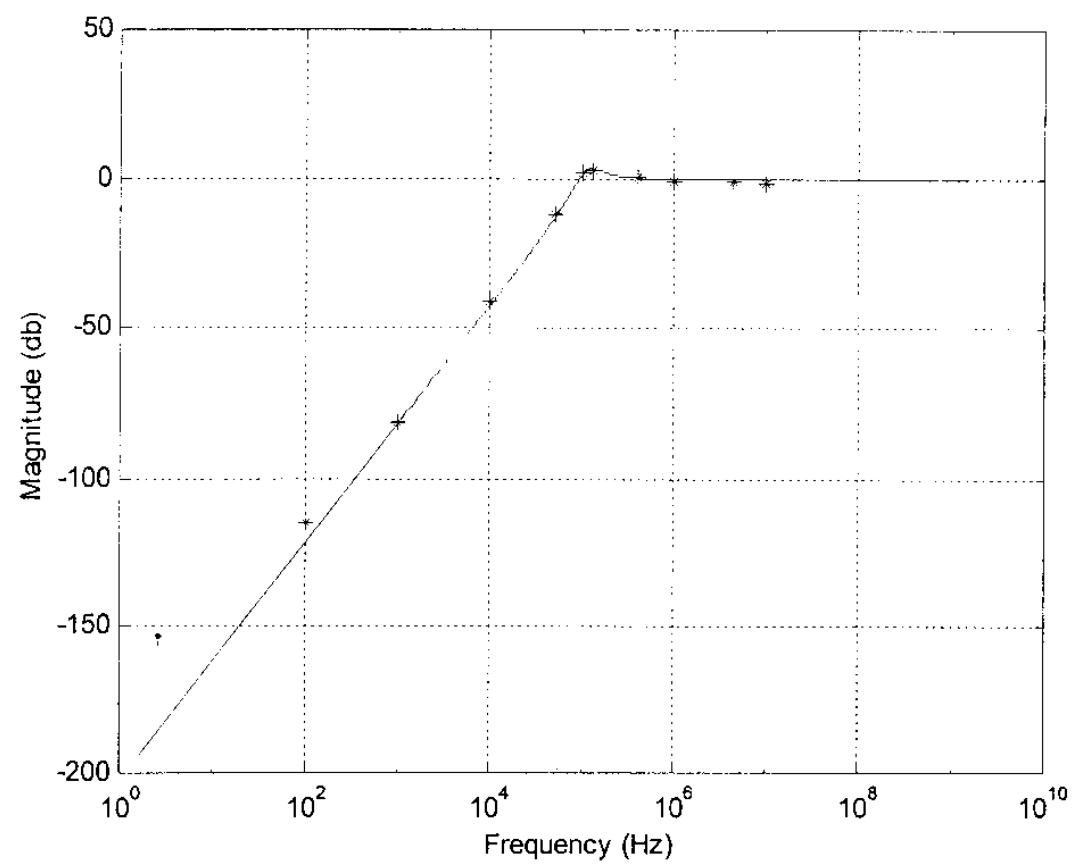

FIGURE 4 Calculated (-) and simulated (**) current-mode highpass response.

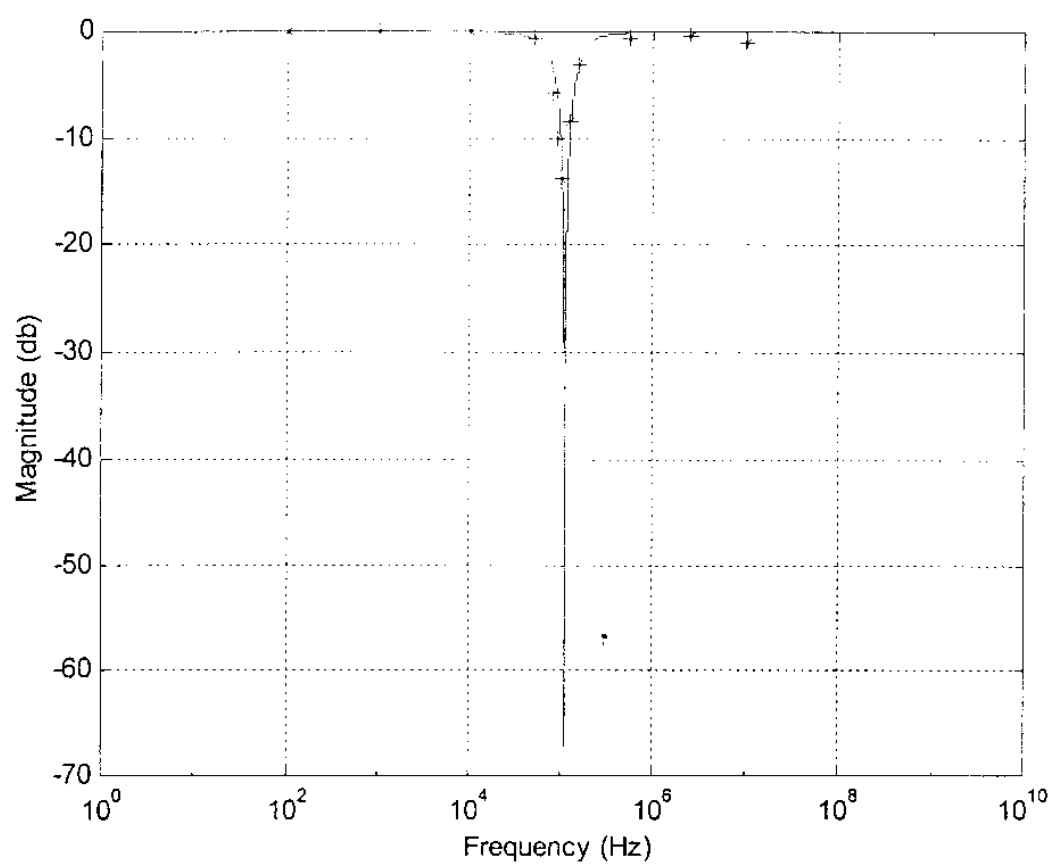

FIGURE 5 Calculated (-) and simulated (**) current-mode notch response. 


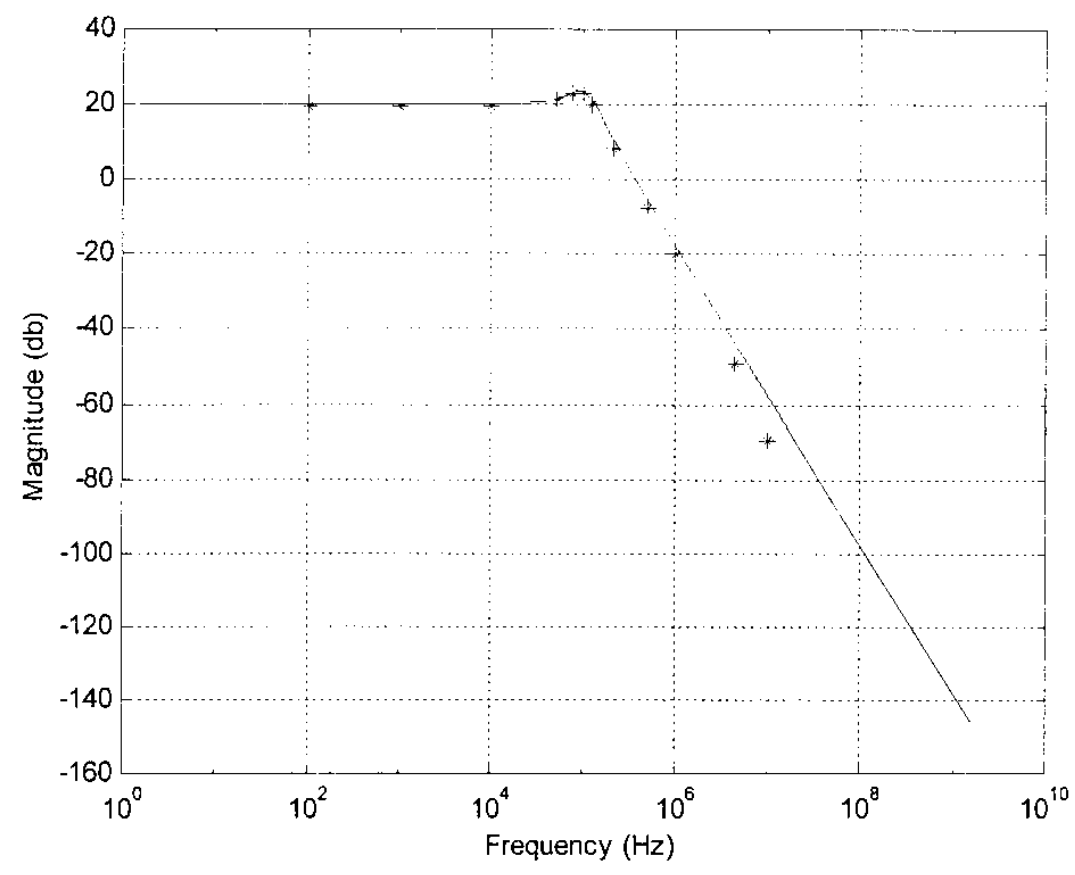

FIGURE 6 Calculated (-) and simulated (**) voltage-mode lowpass response.

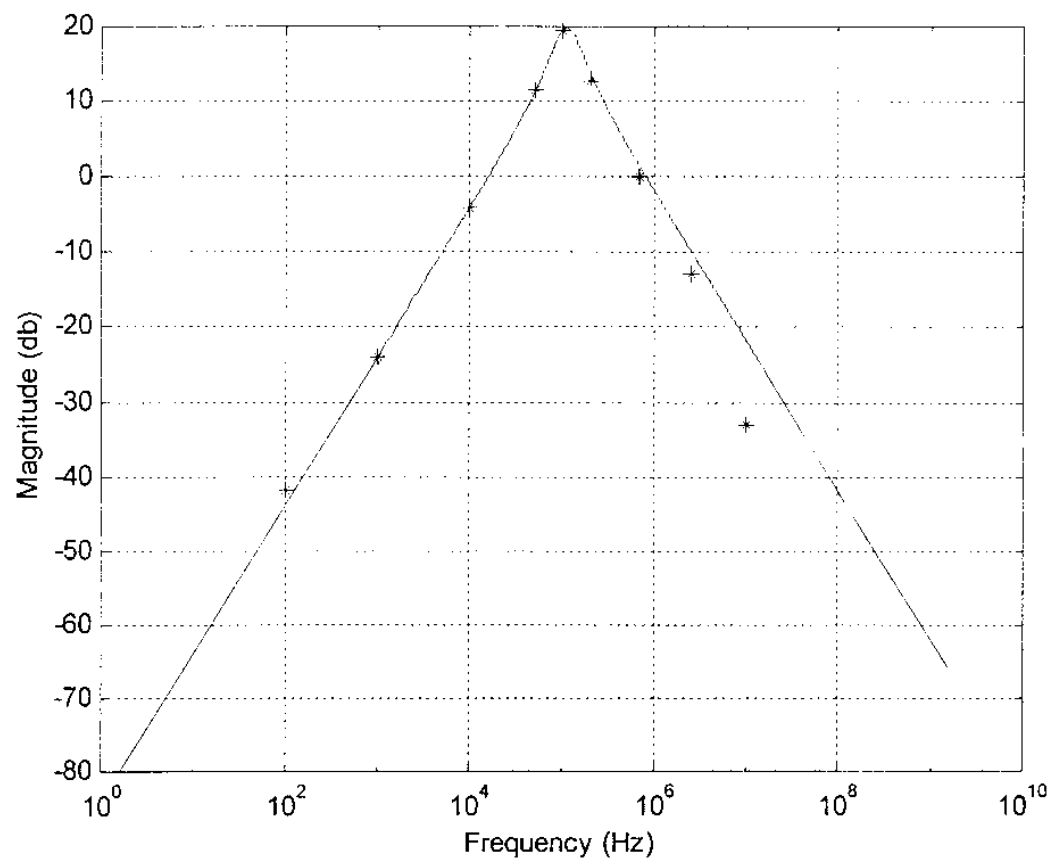

FIGURE 7 Calculated (-) and simulated (**) voltage-mode bandpass response. 


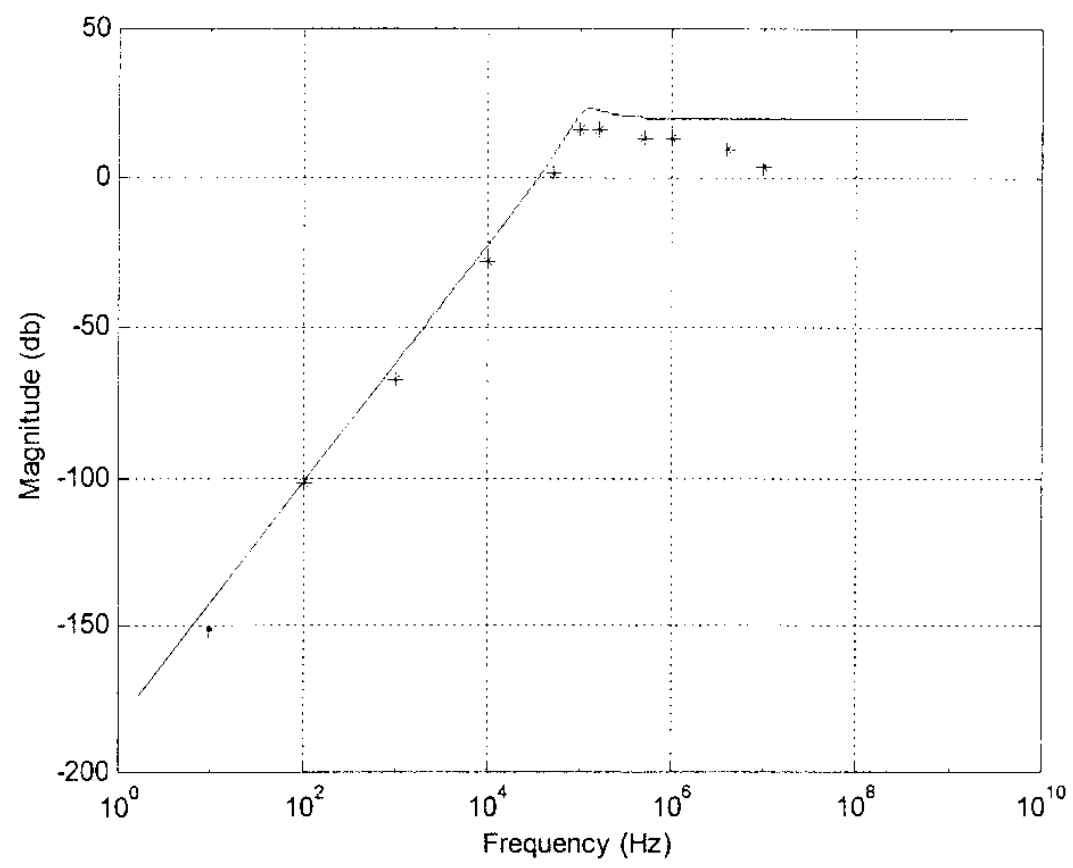

FIGURE 8 Calculated $(-)$ and simulated (**) voltage-mode highpass response.

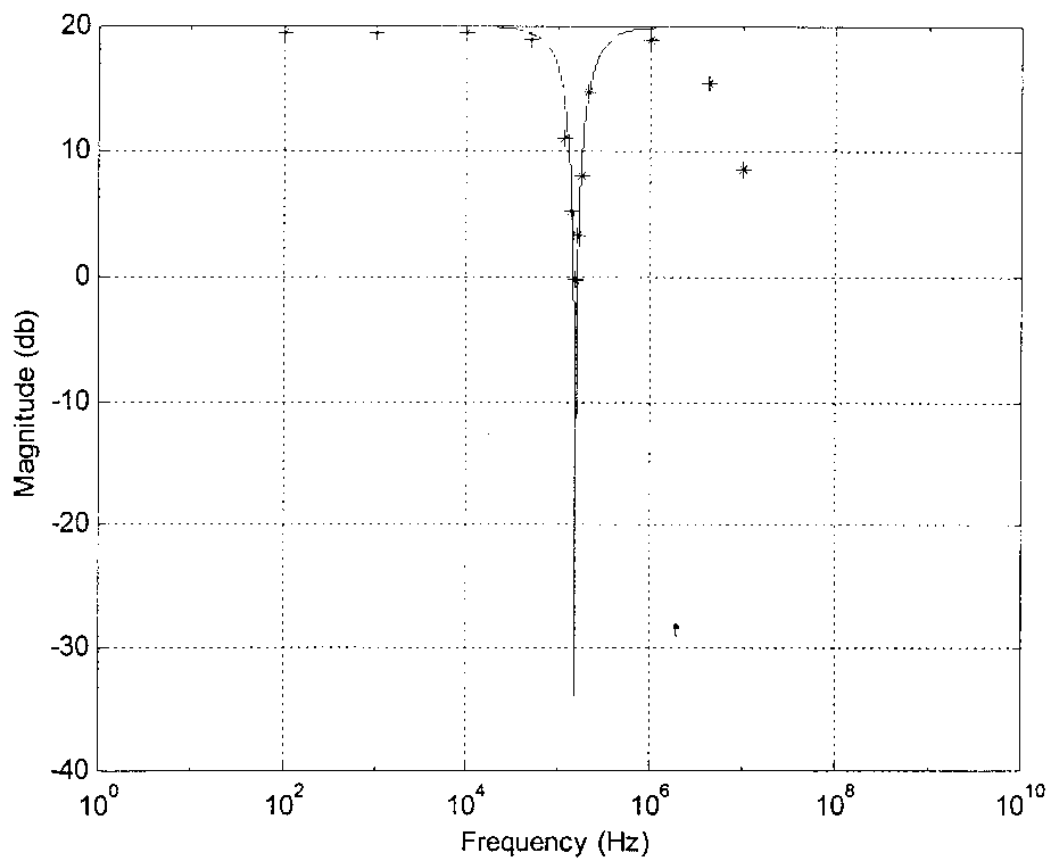

FIGURE 9 Calculated ( - ) and simulated $(* *)$ voltage-mode notch response. 


\section{SIMULATION RESULTS}

The proposed circuit was simulated using the PSPICE circuit simulation program. The CCIIs were modeled using the model reported in Ref. [27] with $R_{x}=50 \Omega, R_{y}=10 \mathrm{M} \Omega, R_{z}=3 \mathrm{M} \Omega$, and $C_{z}=4.5 \mathrm{pF}$. The results obtained from a current-mode LPF, current-mode BPF, currentmode HPF, and current-mode notch with $C_{1}=C_{2}=1 \mathrm{nF}, \quad R_{1}=R_{2}=R_{4}=R_{5}=$ $R_{6}=1 \mathrm{k} \Omega$, and $R_{3}=2 \mathrm{k} \Omega$ are shown in Figures 2-5. The results obtained from a voltage-mode $\mathrm{LPF}$, voltage-mode $\mathrm{BPF}$, and voltage-mode $\mathrm{HPF}$ with $C_{1}=C_{2}=1 \mathrm{nF}$, $R_{1}=R_{2}=R_{4}=R_{5}=R_{6}=1 \mathrm{k} \Omega, R_{3}=2 \mathrm{k} \Omega$, and $R_{7}=10 \mathrm{k} \Omega$ are shown in Figures 6-8. The results obtained from a notch with $C_{1}=C_{2}=1 \mathrm{nF}, R_{1}=R_{2}=R_{5}=R_{6}=1 \mathrm{k} \Omega$, $R_{3}=R_{4}=2 \mathrm{k} \Omega$, and $R_{7}=10 \mathrm{k} \Omega$ are shown in Figure 9. Figures 2-9 also show calculations made using Eqs. (1) and (3)-(6). It appears from Figures $2-9$ that the simulated and calculated results are in fairly good agreement.

\section{CONCLUSIONS}

In this article, a new mixed-mode biquad circuit has been presented. The circuit uses five CCIIs and can realize all the standard biquad filter responses. The parameters of the filter responses enjoy independent electronic tunability and low passive sensitivities. The circuit can realize mixed-mode filter responses. Thus, a voltage input may result in either a current or a voltage output. Also, a current input may result in either a current or voltage output. While the simulation results confirm the theory presented in this article, the discrepancies between the calculated and simulated results are attributed to the simplified model used in the analysis.

\section{References}

[1] Roberts, G. W. and Sedra, A. S. (1989). All current-mode frequency selective circuits. Electronics Letters, 25, 759-761.

[2] Cabeza, R. and Carlosena, A. (1997). Analog universal active device: Theory, design and applications. Analog Integrated Circuits and Signal Processing, 12, 153-168.

[3] Abuelma'atti, M. T. and Shabra, A. M. (1996). A novel current-conveyor-based universal current-mode filter. Microelectronics Journal, 27, 471-475.

[4] Senani, R. (1996). A simple approach of deriving single-input-multiple-output current-mode biquad filters. FREQUENZ, 50, 124-127.

[5] Chang, C.-M. (1997). Universal active current filter with three inputs and one output using plus-type CCIIs. Electronics Letters, 33, 1207-1208.

[6] Ozoguz, S. and Acar, C. (1997). Universal current-mode filter with reduced number of active and passive components. Electronics Letters, 33, 948-949.

[7] Hou, C.-L. and Wu, J.-S. (1997). Universal cascadable current-mode biquad using only four CCIIs. International Journal of Electronics, 82, 125-129; see erratum, in 87, (2000), 511.

[8] Karybakas, C. A. and Papazoglou, C. A. (1999). Low-sensitive CCII-based biquadratic filters offering electronic frequency shifting. IEEE Transactions on Circuits and Systems-II: Analog and Digital Signal Processing, 46, $527-539$.

[9] Ozoguz, S., Toker, A. and Cicekoglu, O. (1999). New current-mode universal filters using only four (CCII+)s. Microelectronics Journal, 30, 255-258.

[10] Toker, A., Ozoguz, S. and Cicekoglu, O. (2000). A new current-mode multifunction filter with minimum components using dual-output current conveyors. IEICE Transactions: Fundamentals, E83-A, 2382-2384.

[11] Toker, A. and Ozoguz, S. (2000). Insensitive current-mode universal filter using dual output current conveyors. International Journal of Electronics, 87, 667-674.

[12] Ozoguz, S., Acar, C., Toker, A. and Gunes, E. O. (2001). Derivation of low-sensitivity current-mode CCII-based filters. IEE Proceedings-Circuits Devices Systems, 138, 115-120.

[13] Hwang, Y.-S., Hung, P.-T., Chen, W. and Liu, S.-I. (2002). Systematic generation of current-mode linear transformation filters based on multiple output CCIIS. Analog Integrated Circuits and Signal Processing, 32, $123-134$ 
[14] Novotny, V. and Vrba, K. (2002). Novel voltage- and current-mode filter design. Proceedings of Asia Pacific Conference on Circuits and Systems, pp. 229-232.

[15] Soliman, A. M. (1998). Current conveyor filters: classification and review. Microelectronics Journal, 29 , 133-149.

[16] Higashimura, M. and Fukui, Y. (1996). Universal filter using plus-type CCIIs. Electronics Letters, 32, 810-811.

[17] Horng, J.-W., Tsai, C.-C. and Lee, M.-H. (1996). Novel universal voltage-mode biquad filter with three inputs and one output using only two current conveyors. International Journal of Electronics, 80, 543-546.

[18] Horng, J.-W., Lay, J.-R., Chang, C.-W. and Lee, M.-H. (1997). High input impedance voltage-mode multifunction filters using plus-type CCIIs. Electronics Letters, 33, 472-473.

[19] Liu, S.-I. and Lee, J.-L. (1997). Voltage-mode universal filters using two current conveyors. International Journal of Electronics, 82, 145-149.

[20] Horng, J.-W., Lee, M.-H., Cheng, H.-C. and Chang, C.-W. (1997). New CCII-based voltage-mode universal biquadratic filter. International Journal of Electronics, 82, 151-155.

[21] Chang, C.-M. (1997). Multifunction biquadratic filters using current conveyors. IEEE Transactions on Circuits and Systems-II: Analog and Digital Signal Processing, 44, 956-958.

[22] Chang, C.-M. and Lee, M.-J. (1999). Voltage-mode multifunction filter with single input and three outputs using two compound current conveyors. IEEE Transactions on Circuits and Systems-I: Fundamental Theory and Applications, 46, 1364-1365.

[23] Chang, C.-M. and Tu, S.-H. (1999). Universal voltage-mode filter with four inputs and one output using two CCII+s. International Journal of Electronics, 86, 305-309.

[24] Ramirez-Angulo, J., Robinson, M. and Sanchez-Sinencio, E. (1992). Current-mode continuous-time filters: two design approaches. IEEE Transactions on Circuits and Systems-II: Analog and Digital Signal Processing, 39, $337-341$.

[25] Soliman, A. M. (1996). Mixed-mode biquad circuits. Microelectronics Journal, 27, 591-594.

[26] Toker, A., Cicekoglu, O., Ozcan, S. and Kuntman, H. (2001). High-output-impedance type continuous-time multifunction filter with minimum active elements. International Journal of Electronics, 88, 1085-1091.

[27] Svoboda, J. A. (1994). Comparison of RC op.amp. and RC current conveyor filters. International Journal of Electronics, 76, 615-626. 

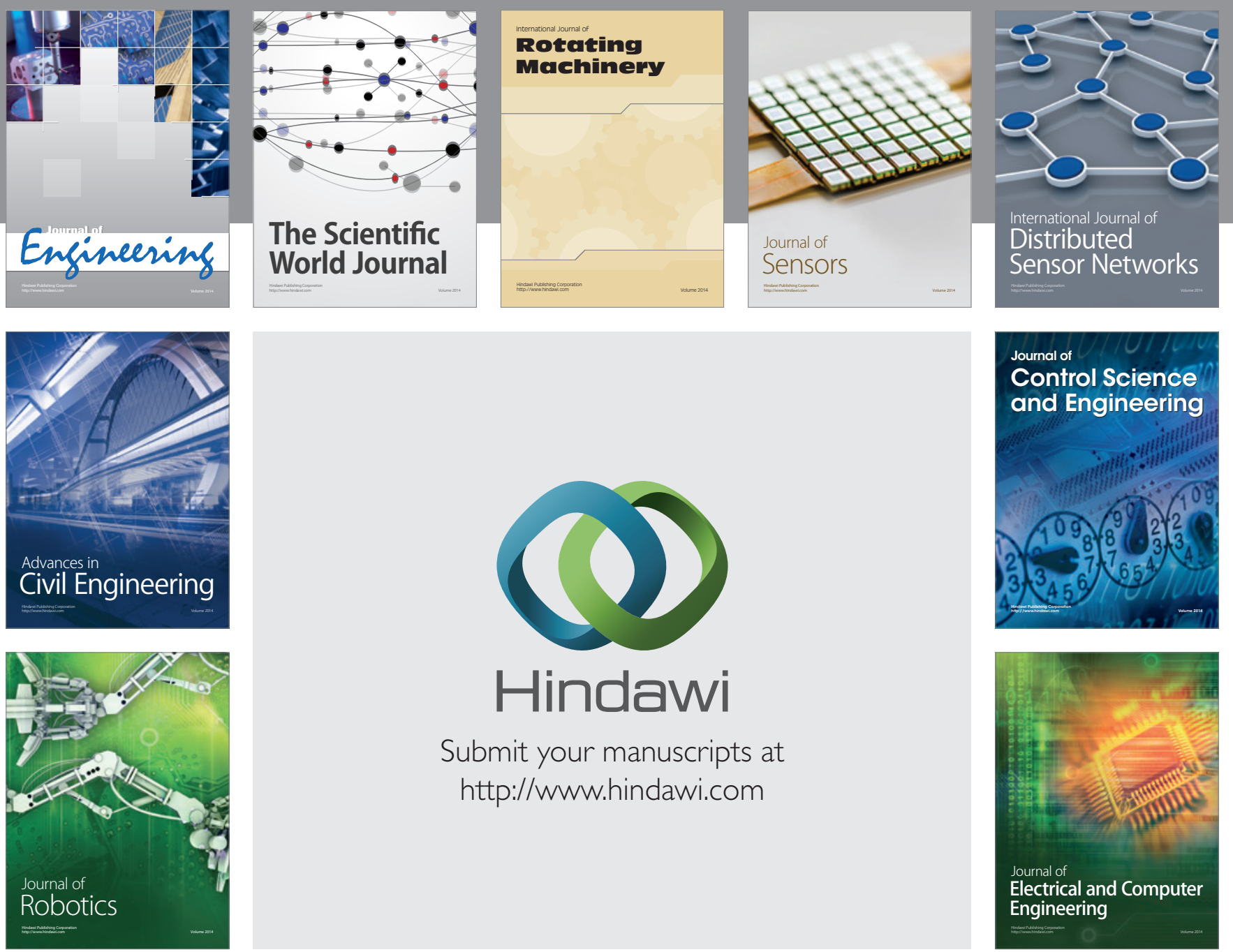

Submit your manuscripts at

http://www.hindawi.com
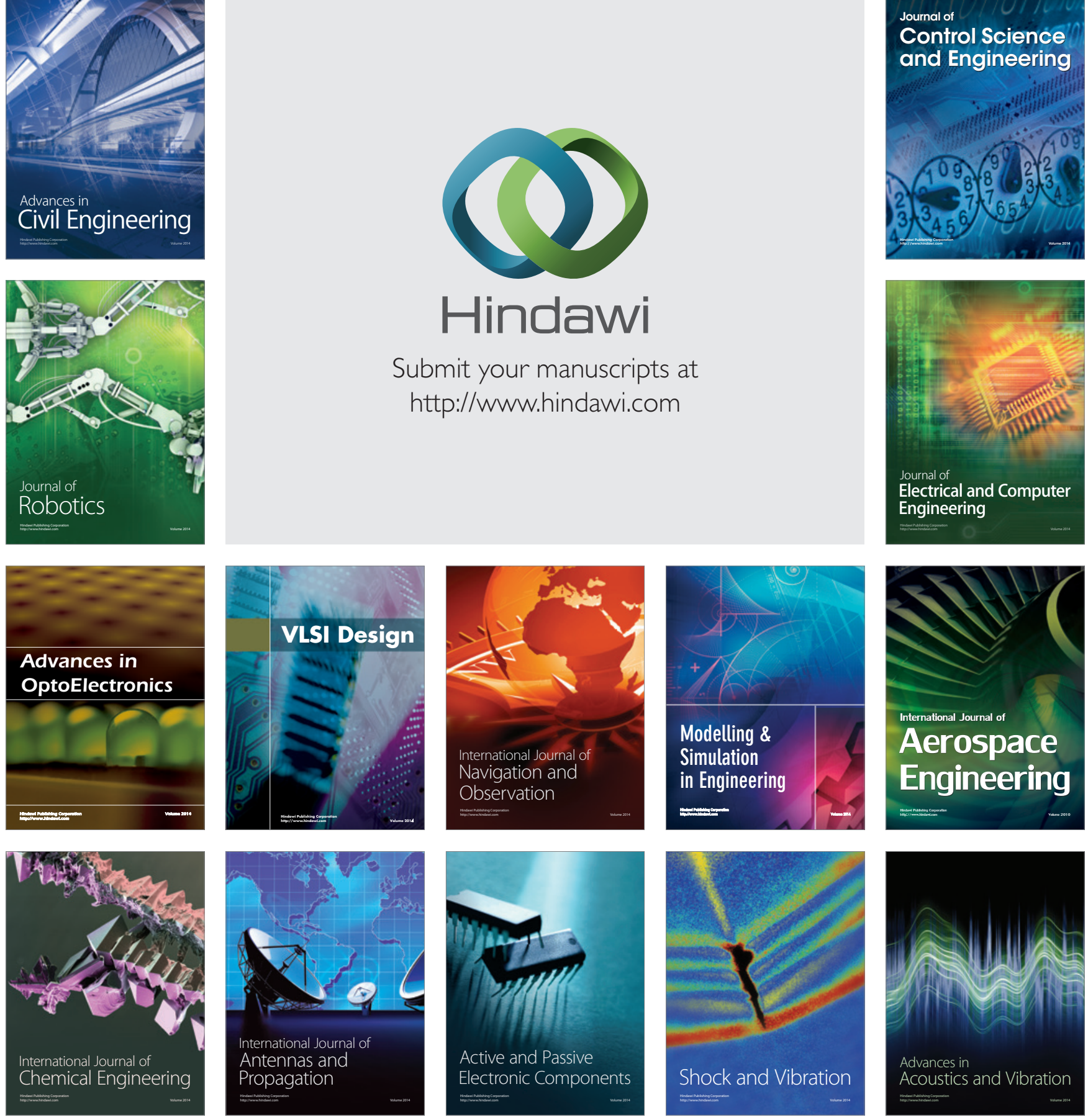